\title{
The effect of magneto-crystalline anisotropy on the properties of hard and soft magnetic ferrite nanoparticles
}

\author{
Hajar Jalili ${ }^{1}$, Bagher Aslibeiki ${ }^{* 1} \S$, Ali Ghotbi Varzaneh ${ }^{2,3}$ and Volodymyr A. Chernenko ${ }^{3,4}$
}

\author{
Full Research Paper \\ Address: \\ 1Department of Physics, University of Tabriz, Tabriz 51666-16471, \\ Iran, ${ }^{2}$ Department of Physics, Isfahan University of Technology, \\ Isfahan, 84156-83111, Iran, ${ }^{3}$ BCMaterials and University of Basque \\ Country (UPV/EHU), Sarriena s/n, Leioa 48940, Spain and \\ ${ }^{4}$ Ikerbasque, Basque Foundation for Science, 48013, Bilbao, Spain \\ Email: \\ Bagher Aslibeiki* - b.aslibeiki@tabrizu.ac.ir \\ * Corresponding author \\ § Tel: +98 4133393334 ; Fax: +98 4133341244 \\ Keywords: \\ anisotropy; cobalt; ferrite; Henkel plots; hyperthermia therapy; \\ nanoparticles; Rietveld refinement
}

Beilstein J. Nanotechnol. 2019, 10, 1348-1359.

doi:10.3762/bjnano.10.133

Received: 26 February 2019

Accepted: 18 June 2019

Published: 03 July 2019

Associate Editor: S. A. Claridge

(C) 2019 Jalili et al.; licensee Beilstein-Institut. License and terms: see end of document.

\begin{abstract}
Recent advances in the field of magnetic materials emphasize that the development of new and useful magnetic nanoparticles (NPs) requires an accurate and fundamental understanding of their collective magnetic behavior. Studies show that the magnetic properties are strongly affected by the magnetic anisotropy of NPs and by interparticle interactions that are the result of the collective magnetic behavior of NPs. Here we study these effects in more detail. For this purpose, we prepared $\mathrm{Co}_{x} \mathrm{Fe}_{3-x} \mathrm{O}_{4} \mathrm{NPs}$, with $x=0-1$ in steps of 0.2 , from soft magnetic $\left(\mathrm{Fe}_{3} \mathrm{O}_{4}\right)$ to hard magnetic $\left(\mathrm{CoFe}_{2} \mathrm{O}_{4}\right)$ ferrite, with a significant variation of the magnetic anisotropy. The phase purity and the formation of crystalline NPs with a spinel structure were confirmed through Rietveld refinement. The effect of Co doping on structure, morphology and magnetic properties of $\mathrm{Co}_{x} \mathrm{Fe}_{3-x} \mathrm{O}_{4}$ samples was investigated. In particular, we examined the interparticle interactions in the samples by $\delta m$ graphs and Henkel plots that have not been reported before in literature. Finally, we studied the hyperthermia properties and observed that the heat efficiency of soft $\mathrm{Fe}_{3} \mathrm{O}_{4}$ is about 4 times larger than that of hard $\mathrm{CoFe}_{2} \mathrm{O}_{4}$ ferrite, which was attributed to the high coercive field of samples compared with the external field amplitude.
\end{abstract}

\section{Introduction}

Technological advances in various fields have motivated the design and the fabrication of nanostructures with tuned and improved properties. Among nanostructured materials, magnetic nanoparticles (NPs) are interesting from both fundamental and technological points of view [1,2]. In recent years, ferrite nano- particles with the general formula of $\mathrm{MFe}_{2} \mathrm{O}_{4}(\mathrm{M}=\mathrm{Fe}, \mathrm{Co}, \mathrm{Ni}$, $\mathrm{Mn}$ ) have attracted great attention of researchers due to their potential applications in biomedicine and industry [3]. Magnetic anisotropy and interparticle interactions are important parameters that affect the magnetic properties and application fields of 
ferrite nanoparticles $[1,4]$. For example, NPs to be applied for data storage or magnetic recording must have a high coercivity, which is directly related to their magnetic anisotropy (the high coercivity keeps the recorded bits from being demagnetized) $[5,6]$. Magnetic interactions (e.g., exchange and dipolar interactions) have a strong effect on the magnetic behavior of a NP system (e.g., coercivity and blocking temperature) $[7,8]$ and its potential for different applications. For example, there may be unfavorable effects in biomedical applications, such as aggregation of nanoparticles in different parts of the body [9]. Hence, the study of this kind of interactions is of particular importance, both from a practical and a fundamental point of view. Recently, Muscas et al. [1] studied the magnetic behavior of mixed cobalt-nickel and pure cobalt ferrite NPs by using a random anisotropy model. Their results showed that the overall magnetic properties are the equilibrium of the interplay between the interparticle interactions and the anisotropy of the single particles. The authors of this paper believe that this study is of fundamental importance to understand the physics of nanoparticle ensembles, which, in turn, is needed to develop technological applications of these systems. Among ferrites, $\mathrm{CoFe}_{2} \mathrm{O}_{4}$ NPs are of considerable interest because of their moderate saturation magnetization, good chemical stability and high intrinsic magnetocrystalline anisotropy at room temperature [10]. The anisotropy constant of $\mathrm{CoFe}_{2} \mathrm{O}_{4}\left(K=2 \times 10^{5} \mathrm{~J} \cdot \mathrm{m}^{-3}\right)$ is nearly one order of magnitude larger than that of $\mathrm{Fe}_{3} \mathrm{O}_{4}$ [11-13]. $\mathrm{Fe}_{3} \mathrm{O}_{4}$ NPs have been studied extensively for bio-medical applications, such as drug delivery [14], magnetic resonance imaging (MRI) and especially magnetic hyperthermia therapy, which is one of the efficient and new approaches for cancer treatment $[4,15]$. When magnetic NPs concentrated in tumor tissue are exposed to an ac magnetic field, the electromagnetic energy is converted into thermal energy, and the generated heat is used to destroy cancer cells through the elevated temperatures $[16,17]$. The heating efficiency of the NPs as heat sources under ac magnetic fields is often denominated as specific absorption rate (SAR), which is directly related to the area of the magnetic hysteresis loop of the nanoparticles by the following formula $[18,19]$ :

$$
\mathrm{SAR}=\frac{f}{c} \oint M(t) \mathrm{d} H_{\mathrm{ac}}=A \cdot f
$$

where $f$ is the field frequency, $c$ is the weight concentration of the material and $A$ is the area of the hysteresis loop. Size and shape of the particles, saturation magnetization and magnetic anisotropy, as well as field amplitude and frequency strongly affect the hyperthermia output of a NP system [15,20,21]. Sathya et al. prepared $\mathrm{Co}_{x} \mathrm{Fe}_{3-x} \mathrm{O}_{4}$ nanocubes by a thermal decomposition method and showed that nanoparticles of $18-20 \mathrm{~nm}$ in size and a Co fraction of $x=0.5-0.7$ have the highest SAR value and are suitable for hyperthermia applications [12]. Nemati et al. prepared iron oxide nanodiscs and compared their heating efficiency with spherical NPs of similar volume at different field strengths [21]. Their results indicated that the heating efficiency obtained for spherical nanoparticles is smaller than that measured for nanodiscs of similar volumes, especially at low field strengths. Barrera et al. prepared $\mathrm{Co}_{1-x} \mathrm{Zn}_{x} \mathrm{Fe}_{2} \mathrm{O}_{4}$ NPs and studied the dynamic energy losses of nanoparticles under an extended range of applied magnetic field strengths. They show that NPs with a larger anisotropy reveal smaller energy losses [22]. For a more systematic study of the effect of magnetic anisotropy and magnetic interactions on properties of magnetic nanoparticles, in this work, a series of $\mathrm{Co}_{x} \mathrm{Fe}_{3-x} \mathrm{O}_{4}(0 \leq x \leq 1)$ NPs was synthesized using a co-precipitation method. The effect of Co doping on the structural, magnetic and hyperthermia properties of $\mathrm{Co}_{x} \mathrm{Fe}_{3-x} \mathrm{O}_{4}$ nanoparticles has been studied. We report a detailed study of the magnetic interactions in the samples through field-dependent measurements of remanent magnetization. In order to investigate the magnetic interactions the Henkel plot method was used, which is an effective and powerful method.

\section{Results and Discussion $X$-ray diffraction}

The phase purity of the samples was confirmed by X-ray diffraction (XRD) analysis. Figure 1a shows XRD patterns of $\mathrm{Co}_{x} \mathrm{Fe}_{3-x} \mathrm{O}_{4}(0 \leq x \leq 1)$ nanoparticles. No secondary phases are found. The peaks intensities indicate that the samples are highly crystalline. The peaks match well with JCPDS cards (no. 01-088-0866 for Fe ferrite; no. 01-088-2152 for $\mathrm{Fe}-\mathrm{Co}$ ferrites and no. 01-079-1744 for Co ferrite) indicating the formation of a cubic spinel structure with the space group $F d-3 m$ (no. 227). Figure 1b showas that the representative (440) reflection shifts towards lower angles with cobalt ions increasingly substituting iron ions in the magnetite structure. This indicates an increase of the interplane distances $(d)$ in the spinel structure. Similar results have been reported for $\mathrm{Ni}_{x} \mathrm{Co}_{1-x} \mathrm{Fe}_{2} \mathrm{O}_{4} \mathrm{NPs}$ by Caetano and co-workers [15].

According to Bragg's law, $\lambda=2 d \cdot \sin \theta$, ( $\lambda$ is the wavelength of $\mathrm{X}$-ray wavelength, here $\lambda=0.154 \mathrm{~nm}$, and $\theta$ is the diffraction angle), a shift of $\theta$ to lower values indicates an increasing lattice spacing $d$ that is directly related to the lattice constant $a$ as:

$$
\begin{aligned}
a & =d \sqrt{\left(h^{2}+k^{2}+l^{2}\right)}, \\
V_{\mathrm{uc}} & =a^{3},
\end{aligned}
$$

where $h, k, l$ are the Miller indices. The values of $a$ and and the unit-cell volume $V_{\text {uc }}$ for all samples were calculated by Equa- 

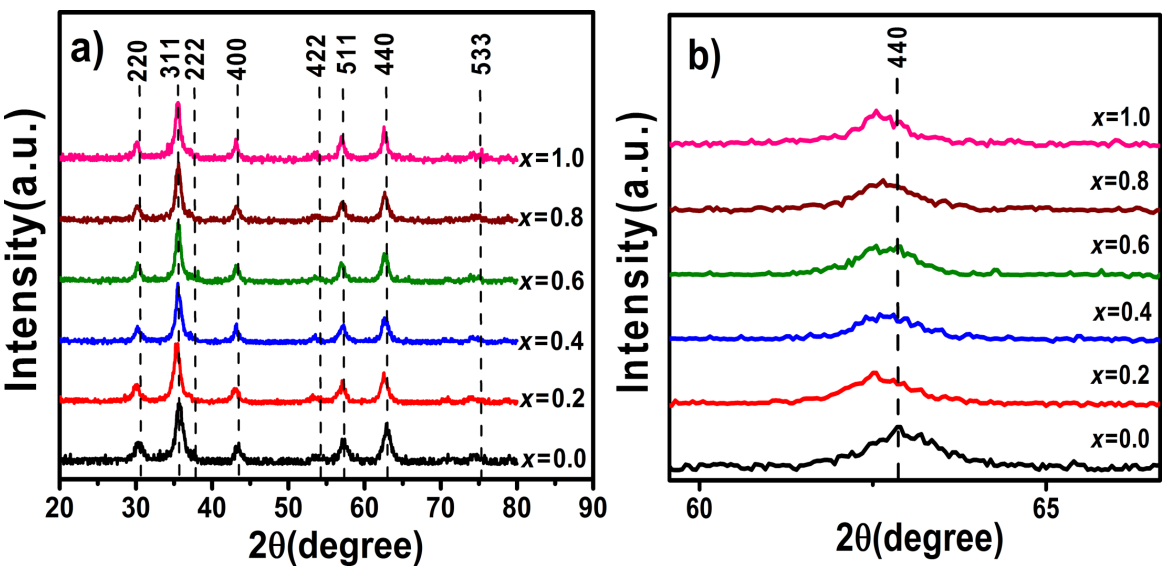

Figure 1: (a) XRD patterns of the $\mathrm{Co}_{x} \mathrm{Fe}_{3-x} \mathrm{O}_{4}(0 \leq x \leq 1)$ nanoparticles. (b) Shift of the $(440)$ reflection.

tion 2 and are listed in Table 1. These values are in good agreement with the values reported before for $\mathrm{Co}_{x} \mathrm{Fe}_{3-x} \mathrm{O}_{4}(0 \leq x \leq 1)$ nanoparticles [23].

The radii of $\mathrm{Co}^{2+}$ ions (A-site: $58 \AA$, B-site: $74 \AA$ ) are slightly different than those of either $\mathrm{Fe}^{2+}$ ions (A-site: $61 \AA$, B-site: $78 \AA$ ) or $\mathrm{Fe}^{3+}$ ions (A-site: $49 \AA$, B-site: $64 \AA$ ) [24]. Therefore, the unsystematic variations and insignificant (in the error range) difference in the lattice constant could be attributed to the change of the cation distribution in the A-and B-sites.

The XRD patterns of the samples were analyzed using the Rietveld refinement method implemented in the the "FullProf Suite" software. As an example, the Rietveld refinement pattern of the $\mathrm{Co}_{0.2} \mathrm{Fe}_{2.8} \mathrm{O}_{4}$ sample is shown in Figure 2. Table 1 shows that the parameters $a$ and $V_{\text {uc }}$ obtained from Rietveld refinement are in good agreement with those calculated with Equation 2.

The effect of Co doping on the average crystallite size was studied using the Scherrer equation:

$$
\langle D\rangle_{\mathrm{XRD}}=\frac{K \lambda}{\beta \cos \theta},
$$

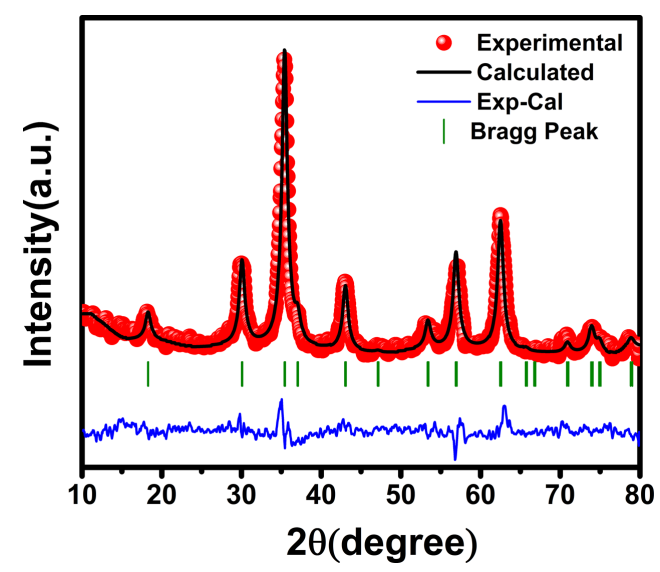

Figure 2: Rietveld-refined XRD pattern of the $x=0.2$ sample.

where $\langle D\rangle_{\mathrm{XRD}}$ is the average crystallite size, $K \approx 0.9$ is the Scherrer constant and $\beta$ is the full width at half-maximum (FWHM) of the XRD peaks. Table 1 shows that the crystallite size increases with increasing cobalt content. The increase of the crystallite size is attributed to the bond energy of Co-O $(397 \mathrm{~kJ} / \mathrm{mol})$, which is smaller than that of $\mathrm{Fe}-\mathrm{O}(407 \mathrm{~kJ} / \mathrm{mol})$ [25]. The smaller bond energy speeds up the crystallization process, thus increasing the crystallite size in the samples.

Table 1: Lattice constant $(a)$, volume of unit cell $\left(V_{\mathrm{uc}}\right)$, crystallite size $\langle D\rangle_{\mathrm{XRD}}$ and mean particle size $\langle D\rangle_{\mathrm{SEM}}$.

\begin{tabular}{|c|c|c|c|c|c|c|}
\hline parameter & $x=0.0$ & $x=0.2$ & $x=0.4$ & $x=0.6$ & $x=0.8$ & $x=1.0$ \\
\hline a $(\AA)$ (from Equation 2) & $8.36(4)$ & $8.40(1)$ & $8.37(1)$ & $8.38(3)$ & $8.37(2)$ & $8.40(1)$ \\
\hline$a(\AA)$ (from Rietveld refinement) & 8.346 & 8.406 & 8.379 & 8.382 & 8.373 & 8.399 \\
\hline$V_{\mathrm{uc}}\left(\AA^{3}\right)$ (from Equation 2) & $584(8)$ & $593(2)$ & $586(2)$ & $588(6)$ & $586(4)$ & $593(2)$ \\
\hline$V_{\text {uc }}\left(\AA^{3}\right)($ Rietveld $)$ & 581.3 & 594.0 & 588.3 & 588.9 & 587.0 & 592.5 \\
\hline$\langle D\rangle_{\mathrm{XRD}}(\mathrm{nm})$ & $7.5 \pm 0.8$ & $8.6 \pm 1.0$ & $9.5 \pm 2.0$ & $10.3 \pm 0.8$ & $9.7 \pm 1.1$ & $13.1 \pm 1.7$ \\
\hline$\langle D\rangle_{\mathrm{SEM}}(\mathrm{nm})$ & $40.3 \pm 8.5$ & $28.7 \pm 7.4$ & $31.5 \pm 6.1$ & $25.8 \pm 6.2$ & $24.0 \pm 5.0$ & $27.1 \pm 6.5$ \\
\hline
\end{tabular}




\section{Microstructure and morphology}

In order to determine the particle size distribution and morphology of the samples, field-emission scanning electron microscopy (FE-SEM) was carried out. Figure 3 shows FE-SEM images of all the samples. The images reveal that particles are in the nanometer range and roughly spherical in shape. The particles size distribution in the samples was determined by measuring the size of 100 particles from the FE-SEM images fitting the size histogram with a log-normal function:

$$
f(D)=\frac{1}{\sqrt{2 \pi} \sigma D} \exp \left[-\frac{\ln ^{2}\left(D / D_{0}\right)}{2 \sigma^{2}}\right],
$$
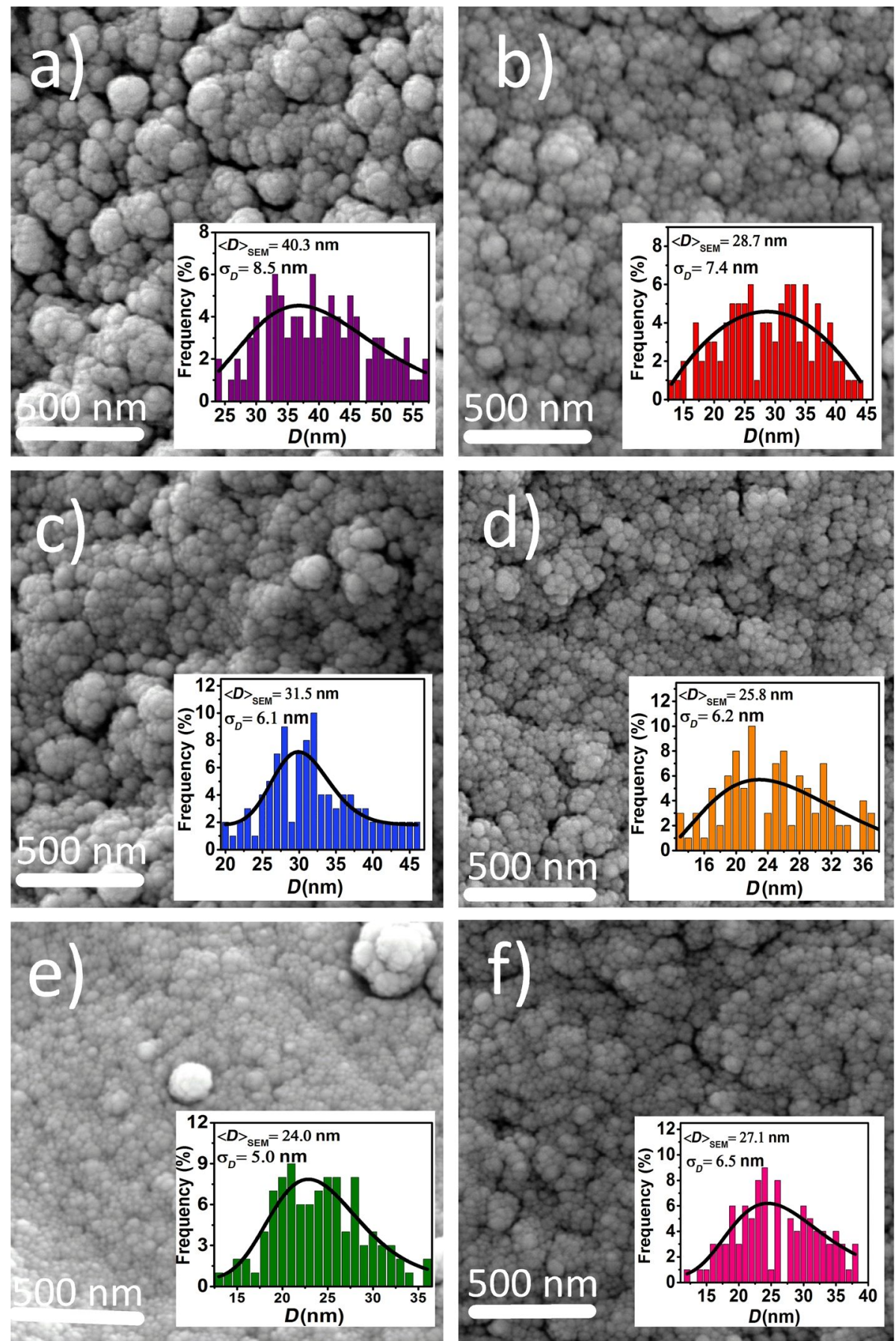

Figure 3: $\mathrm{FE}-\mathrm{SEM}$ images of $\mathrm{Co}_{x} \mathrm{Fe}_{3-x} \mathrm{O}_{4}$ nanoparticles: (a) $x=0.0$; (b) $x=0.2$; (c) $x=0.4$; (d) $x=0.6$; (e) $x=0.8$ and (f) $x=1.0$. Insets show the particle size distribution fitted with a log-normal function (solid line). 
where $D_{0}$ is the median diameter and $\sigma$ is the dispersion. The mean diameter $\langle D\rangle=D_{0} \cdot \exp \left(\sigma^{2} / 2\right)$ and standard deviation $\sigma_{\mathrm{D}}=\langle D\rangle \cdot\left[\exp \left(\sigma^{2}\right)-1\right]^{1 / 2}$ were determined using the fit parameters $D_{0}$ and $\sigma$ and are given in Table 1 . The obtained values of $\langle D\rangle_{\text {SEM }}$ are larger than those obtained from the XRD patterns, which could be attributed to aggregation of the nanoparticles due to the presence of magnetic interactions between nanoparticles. The magnetic interactions are discussed in more detail in the following sections.

The qualitative chemical composition of the samples was investigated by using energy-dispersive X-ray spectroscopy (EDX). Figure 4 shows the EDX spectra for the samples with $x=0.2$, 0.6 and 1. The EDX spectra confirm the presence of $\mathrm{Fe}, \mathrm{Co}$ and $\mathrm{O}$ in the samples. The atomic ratio $\mathrm{Co} / \mathrm{Fe}$ obtained from EDX is in a good agreement with the theoretical stoichiometry for all samples (Figure 4d).

\section{Infrared spectra}

The formation of the spinel phase and its crystal structure were verified by Fourier-transform infrared (FTIR) spectra measured at $300 \mathrm{~K}$ in the wave number range of $400-4000 \mathrm{~cm}^{-1}$. Figure 5 shows the FTIR spectra of the samples.

The absorption band observed at around $3385 \mathrm{~cm}^{-1}$ is attributed to the vibration mode of the $\mathrm{O}-\mathrm{H}$ groups in the $\mathrm{H}_{2} \mathrm{O}$ mol-

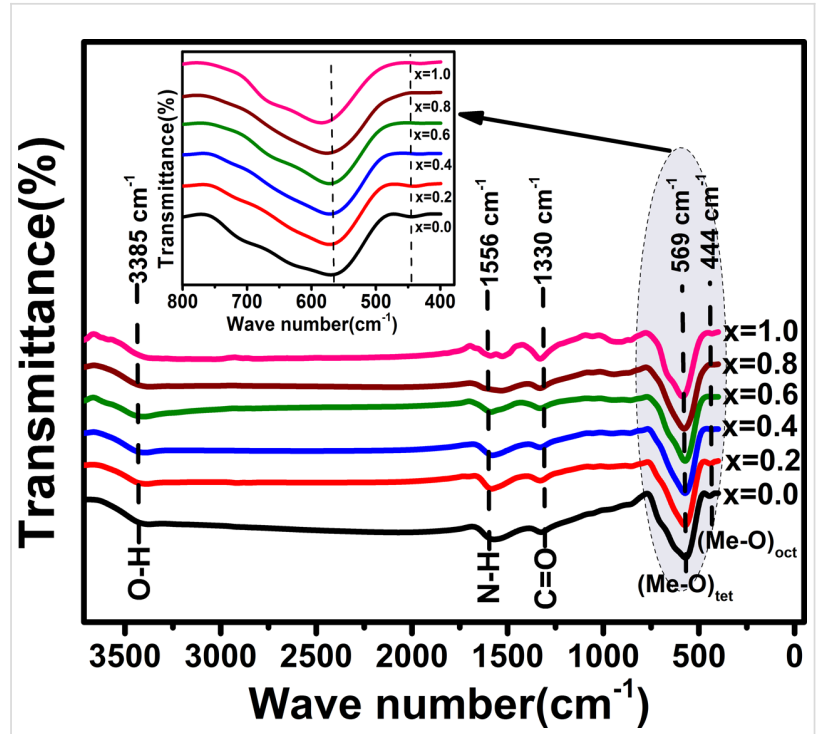

Figure 5: FTIR spectra of $\mathrm{Co}_{x} \mathrm{Fe}_{3-x} \mathrm{O}_{4}$ nanoparticles with $x=0.0,0.2$, $0.4,0.6,0.8$ and 1.0. The inset is the part of the spectra at frequencies below $1000 \mathrm{~cm}^{-1}$.

ecules. The peak observed at around $1556 \mathrm{~cm}^{-1}$ is ascribed to amide II ( $\mathrm{NH}_{2}$ deformation, $\mathrm{N}-\mathrm{H}$ bending) [26] and the absorption peak at around $1330 \mathrm{~cm}^{-1}$ is related to the stretching vibration bands of the carboxylate group $(\mathrm{C}=\mathrm{O})$ [27]. The latter two peaks (1556 and $\left.1330 \mathrm{~cm}^{-1}\right)$ are observed in all samples and
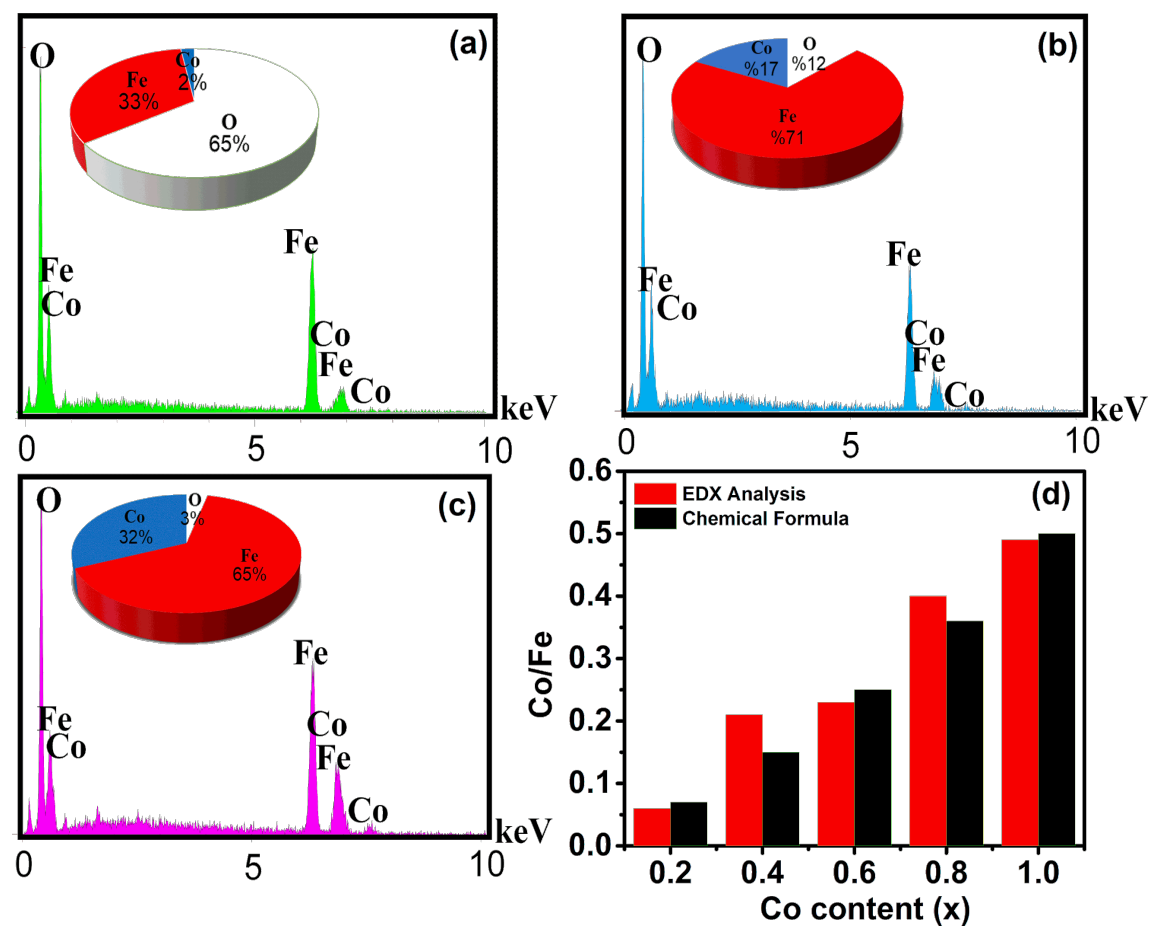

Figure 4: EDX spectra of $\mathrm{Co}_{x} \mathrm{Fe}_{3-x} \mathrm{O}_{4}$ nanoparticles: (a) $x=0.2$; (b) $x=0.6$; and (c) $x=1.0$. (d) Comparison of the Co/Fe atomic ratio obtained from EDX analysis and the theoretical stoichiometry of all samples. 
can be ascribed to the presence of some impurity in the $\mathrm{KBr}$ pellets, which is used for FTIR analysis. Two main absorption bands are observed at frequencies below $1000 \mathrm{~cm}^{-1}$. The band around $569 \mathrm{~cm}^{-1}$ and the band around $444 \mathrm{~cm}^{-1}$ are related to the vibration of metal-oxygen $(\mathrm{Me}-\mathrm{O})$ bonds at tetrahedral and octahedral sites, respectively $[28,29]$. The presence of these two bands confirms the formation of the spinel structure in all the samples.

The inset in Figure 5 shows that the absorption bands related to the tetrahedral site shift towards higher frequencies with increasing cobalt content. This can be explained by considering that the $\mathrm{Co}^{2+}$ ions, being smaller than the $\mathrm{Fe}^{2+}$ ions, tend to occupy both the B-sites and the smaller A-sites (see Figure 6). This mixed occupancy in cobalt-substituted magnetite nanoparticles has been confirmed by Mössbauer spectroscopy [30]. Therefore, it is expected that when cobalt ions substitute iron ions at the A-sites, an increasing $\mathrm{Me}-\mathrm{O}$ bond distance will result. This leads to a weakening of the bond strength and a shift of the peak position towards higher frequencies.

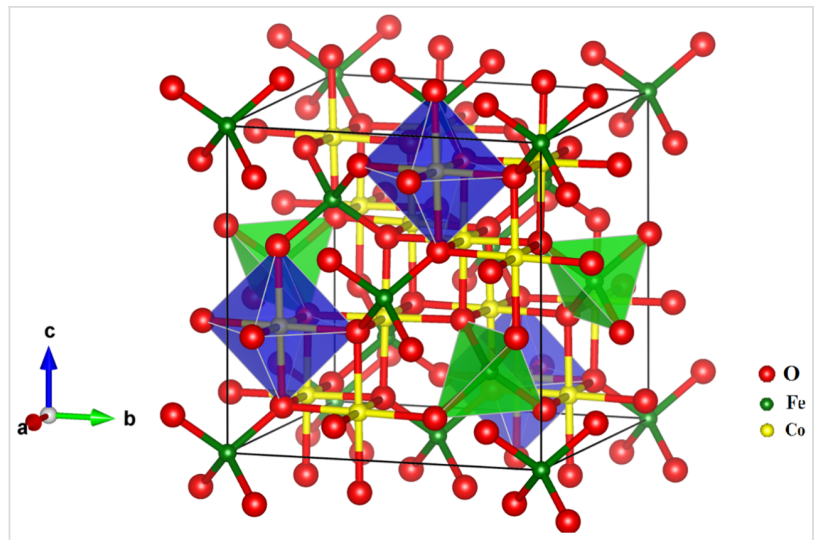

Figure 6: Polyhedral model showing the cubic spinel crystal structure of $\mathrm{CoFe}_{2} \mathrm{O}_{4}$. Green and blue shaded areas correspond to the tetrahedral A-sites and octahedral B-sites, respectively.

\section{Thermogravimetric analysis}

The magnetic properties depend on the percentage of the magnetic material (ferrite) in the sample. Hence, the presence of non-magnetic impurities in the $\mathrm{CoFe}_{2} \mathrm{O}_{4}$ samples was checked by thermogravimetric analysis (TGA). Figure 7 shows two weight-loss stages. The first weight loss (about $2.8 \%$ ), observed in the temperature range of $30-200{ }^{\circ} \mathrm{C}$, is attributed to the vaporization of water from the sample. Since the possible decomposition of spinel ferrite is excluded because of the absence of secondary phases in the XRD patterns, the second weight loss (about $1.2 \%$ ) between 200 and $500{ }^{\circ} \mathrm{C}$ can be attributed to the escape of oxygen atoms from the surface of the NPs [31] and the removal of impurities present in the initial raw materials.

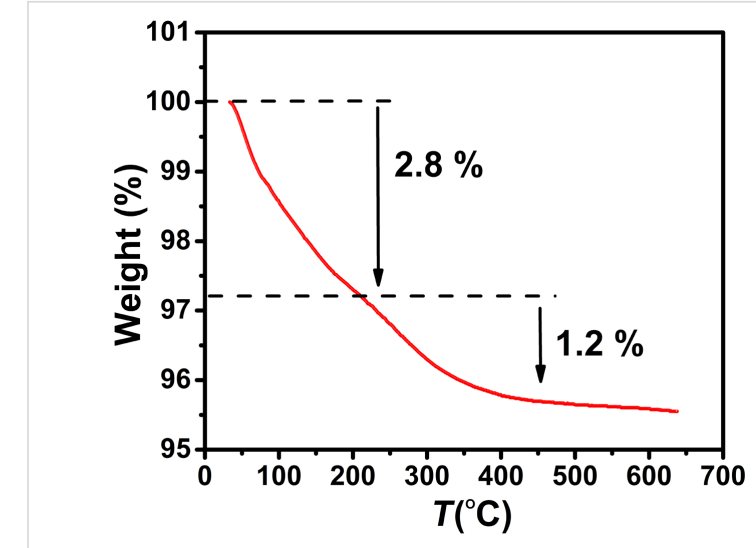

Figure 7: TGA curve of the $\mathrm{CoFe}_{2} \mathrm{O}_{4}$ sample.

\section{Magnetic characterization}

Figure 8 shows the room-temperature magnetic hysteresis curves of the samples. The inset of Figure 8 shows that the magnetic behavior of the samples changes from soft ferrite $\left(\mathrm{Fe}_{3} \mathrm{O}_{4}\right)$ to hard ferrite $\left(\mathrm{CoFe}_{2} \mathrm{O}_{4}\right)$ as the cobalt content increases.

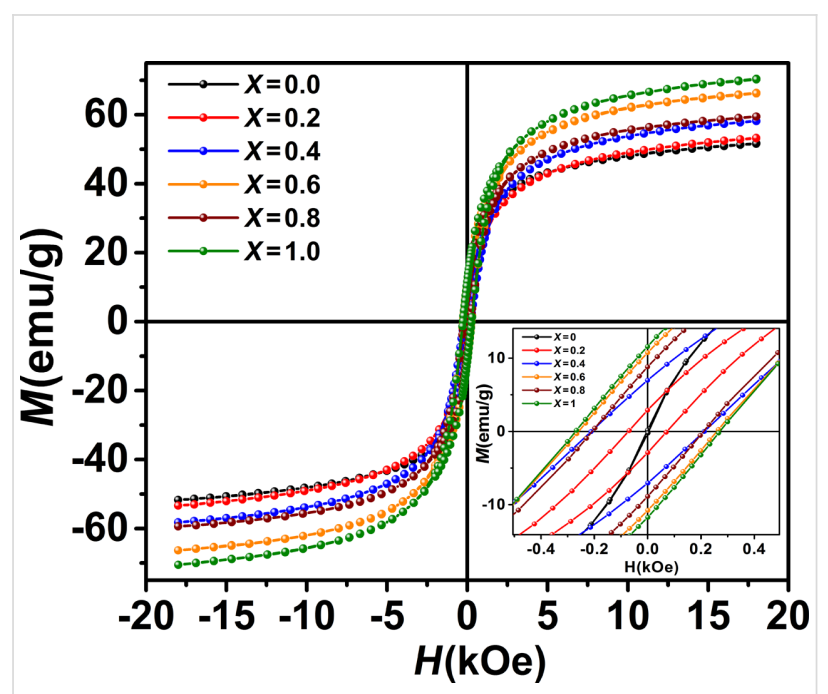

Figure 8: Room-temperature magnetization curves of the $\mathrm{Co}_{x} \mathrm{Fe}_{3-x} \mathrm{O}_{4}$ samples measured. The inset shows the magnetization behavior at low fields.

The values of saturation magnetization $\left(M_{\mathrm{S}}\right)$, remanent magnetization $\left(M_{\mathrm{r}}\right)$ and coercivity $\left(H_{\mathrm{c}}\right)$ obtained from the magnetization curves are given in Table 2.

The difference in magnetization of the ferrites NPs is mainly attributed to the difference in particle size [32,33]. The inset of Figure 9 shows that $M_{\mathrm{S}}$ increases with increasing cobalt content due to increasing the particles size. In fact, the high surface-tovolume ratio in the smaller nanoparticles leads to an increase of 
Table 2: Saturation magnetization $\left(M_{S}\right)$, coercivity $\left(H_{C}\right)$ and remanence $\left(M_{r}\right)$ of the $\mathrm{Co}_{x} \mathrm{Fe}_{3-x} \mathrm{O}_{4}$ samples at room temperature.

\begin{tabular}{lllllll} 
parameter & $x=0$ & $x=0.2$ & $x=0.4$ & $x=0.6$ & $x=0.8$ & $x=1$ \\
\hline$M_{\mathrm{S}}(\mathrm{emu} / \mathrm{g})$ & $51.64 \pm 0.05$ & $53.30 \pm 0.02$ & $58.18 \pm 0.01$ & $66.26 \pm 0.03$ & $59.42 \pm 0.04$ \\
$H_{\mathrm{c}}(\mathrm{Oe})$ & $3.36 \pm 0.65$ & $72.50 \pm 0.32$ & $206.97 \pm 5.35$ & $258.19 \pm 0.99$ & $205.36 \pm 2.67$ & $273.24 \pm 5.33$ \\
$M_{\mathrm{r}}(\mathrm{emu} / \mathrm{g})$ & $0.26 \pm 0.05$ & $2.91 \pm 0.03$ & $7.04 \pm 0.05$ & $10.75 \pm 0.02$ & $8.84 \pm 0.02$
\end{tabular}

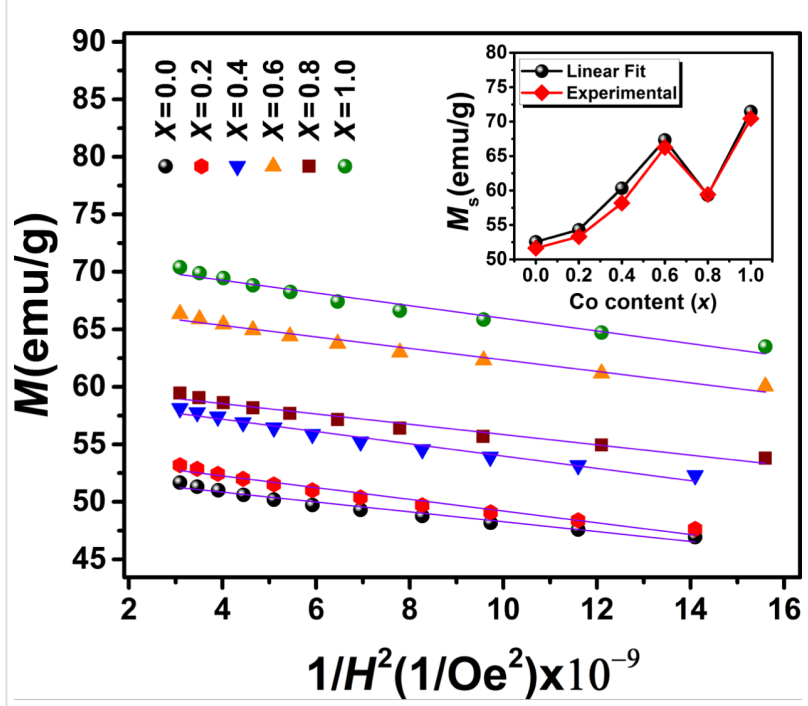

Figure 9: The $\mathrm{M}-1 / \mathrm{H}^{2}$ dependence of the $\mathrm{Co}_{x} \mathrm{Fe}_{3-x} \mathrm{O}_{4}$ samples at high field strengths. Experimental data are marked by symbols. The solid lines represent a linear fit of the experimental data using Equation 6. The inset shows the saturation magnetization values obtained from the linear fits and the hysteresis loop curves.

the surface effects such as spin disorder and dead layer on the surface, eventually resulting in a decrease of the magnetization. The thickness of the surface dead layer $(t)$ equaling to $t=0.56$ and $0.26 \mathrm{~nm}$ for the samples $\mathrm{Fe}_{3} \mathrm{O}_{4}$ and $\mathrm{CoFe}_{2} \mathrm{O}_{4}$, respectively, was obtained as follows $[34,35]$ :

$$
M_{\mathrm{s}}=M_{\mathrm{b}}\left(1-\frac{6 t}{d}\right)
$$

where $d$ is the particle diameter and $M_{\mathrm{b}}$ is the bulk saturation magnetization (93 and $80 \mathrm{emu} / \mathrm{g}$ for the samples $\mathrm{Fe}_{3} \mathrm{O}_{4}$ and $\mathrm{CoFe}_{2} \mathrm{O}_{4}$, respectively) [3,36].

It is expected that Co increases the magnetic anisotropy in the cubic spinel structure. The effective anisotropy constant $\left(K_{\text {eff }}\right)$ of particles was estimated using the law of approach to saturation (LAS), which describes the dependence of the magnetization $(M)$ on the applied magnetic field $(H)$ at high field strengths $\left(H \gg H_{\mathrm{c}}\right)$. According to the LAS, the magnetization near the saturation $\left(M_{\mathrm{S}}\right)$ can be expressed as [3,21]:

$$
M=M_{\mathrm{s}}\left(1-\frac{b}{H^{2}}\right),
$$

where the parameter $b$ is associated with the effective anisotropy constant as [21]:

$$
K_{\text {eff }}=\mu_{0} M_{\mathrm{s}} \sqrt{\frac{15 b}{4}}
$$

To calculate $K_{\text {eff }}$, the experimental curves of $M$ as a function of $1 / H^{2}$ were fitted by Equation 6 at high magnetic field strengths (Figure 9). The obtained values of $b$ and $M_{\mathrm{S}}$ were used to calculate $K_{\text {eff }}$ from Equation 7. The calculated values of $K_{\text {eff }}$ are presented in Table 3. The result for $\mathrm{CoFe}_{2} \mathrm{O}_{4} \mathrm{NPs}$ is in a good agreement with that reported for NPs (ca. $10 \mathrm{~nm}$ ) of the same compound at room temperature $\left(K_{\text {eff }}=3.7 \times 10^{5} \mathrm{erg} / \mathrm{cm}^{3}\right)$ [17]. Figure 10 shows an increasing magnetic anisotropy with increasing cobalt content. This is due to the gradual occupation of the octahedral sites by cobalt ions and the stronger LS coupling originating from their strong orbital angular momentum [37,38]. The drop of anisotropy in the $x=0.8$ sample might be due to the decrease of coercivity (because of the smaller size of the singledomain NPs). It is known that the cobalt ions exhibit a strong anisotropy at the octahedral sites of the cubic spinel structure [39]. Also, Mössbauer spectroscopy showed a relatively high

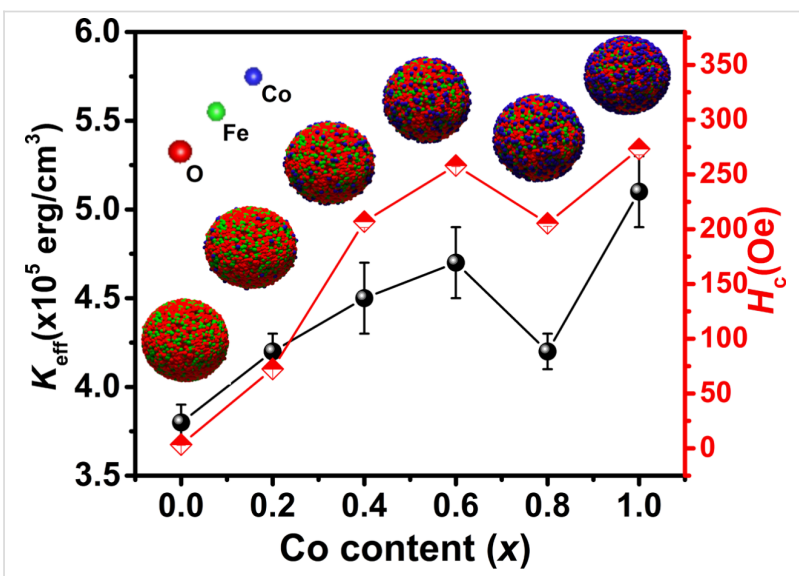

Figure 10: Effective anisotropy constant $\left(K_{\text {eff }}\right)$ and coercivity $\left(H_{\mathrm{c}}\right)$ of the $\mathrm{Co}_{x} \mathrm{Fe}_{3-x} \mathrm{O}_{4}$ samples. 
Table 3: Efective anisotropy constant $\left(K_{\text {eff }}\right)$, reverse field $\left(H_{r}\right)$ and mean interaction field $\left(H_{\text {int }}\right)$ of the $\mathrm{Co}_{x} \mathrm{Fe}_{3-x} \mathrm{O}_{4}$ samples.

\begin{tabular}{llllll} 
parameter & $x=0.0$ & $x=0.2$ & $x=0.4$ & $x=0.6$ & $x=0.8$ \\
\hline$K_{\text {eff }}\left(\times 10^{5} \mathrm{erg}\left(\mathrm{cm}^{3}\right)\right.$ & $3.8 \pm 0.1$ & $4.2 \pm 0.1$ & $4.5 \pm 0.2$ & $4.7 \pm 0.2$ & $4.2 \pm 0.1$ \\
$H_{\mathrm{r}}(\mathrm{Oe})$ & 197.58 & 412.03 & 651.88 & 726.64 & $6.1 \pm 0.2$ \\
$H_{\text {int }}(\mathrm{Oe})$ & - & -62.36 & -77.57 & -42.78 & -84.27
\end{tabular}

number of A-sites occupied by $\mathrm{Co}^{2+}$ ions in the $x=0.8$ sample [40]. Hence, another reason for the sudden drop of the magnetic anisotropy may be attributed to the increasing number of A-sites occupied with $\mathrm{Co}^{2+}$ ions, which leads to a reduced anisotropy because of the less anisotropic environment of the A-sites. Deepak et al. [41] observed a sharp decrease in the anisotropy for $x>0.6$ in $\mathrm{Co}_{x} \mathrm{Fe}_{3-x} \mathrm{O}_{4}$ nanoparticles. They attributed this effect to $\mathrm{Co}-\mathrm{Co}$ interactions at high Co concentrations leading to a reduction of anisotropy, while $\mathrm{Fe}-\mathrm{Co}$ interactions in the lattice increase the magnetocrystalline anisotropy. Figure 10 shows $H_{\mathrm{c}}$ as a function of the cobalt content. The increase of coercivity is mainly related to the increase of anisotropy. An increase of $H_{\mathrm{c}}$ with increasing crystallite size has been reported for single-domain NPs $[13,42]$.

\section{Remanent magnetization}

The analysis of remanent magnetization curves (isothermal remanent magnetization $\left(M^{\mathrm{IRM}}\right)$ and direct current demagneti- zation $\left(M^{\mathrm{DCD}}\right)$ ) measured at $290 \mathrm{~K}$ (Figure 11) allowed us to study the mechanism of interparticle interactions. DCD and IRM curves are given in Figure 11a for all samples.

The parameter $H_{\mathrm{r}}$ shown in the inset of Figure 11a is the remanence coercivity, defined as the reverse field at $M^{\mathrm{DCD}}=0$ [43]. For a system of non-interacting single-domain nanoparticles with uniaxial anisotropy, $M^{\mathrm{IRM}}$ and $M^{\mathrm{DCD}}$ curves are related via the Wohlfarth equation $[9,13]$ :

$$
m^{\mathrm{DCD}}(H)=1-2 m^{\mathrm{IRM}}(H)
$$

where $m^{\mathrm{DCD}}(H)$ and $m^{\mathrm{IRM}}(H)$ are normalized to the remanence saturation values $M_{\mathrm{s}}^{\mathrm{IRM}}$ and $M_{\mathrm{s}} \mathrm{DCD}$ of the DCD and the IRM curve, respectively. The interactions in the samples can be quantitatively investigated by the Henkel plot $\left(m^{\mathrm{DCD}}\right.$ as a function of $m^{\mathrm{IRM}}$ ). According to the Wohlfarth relationship (Equa-
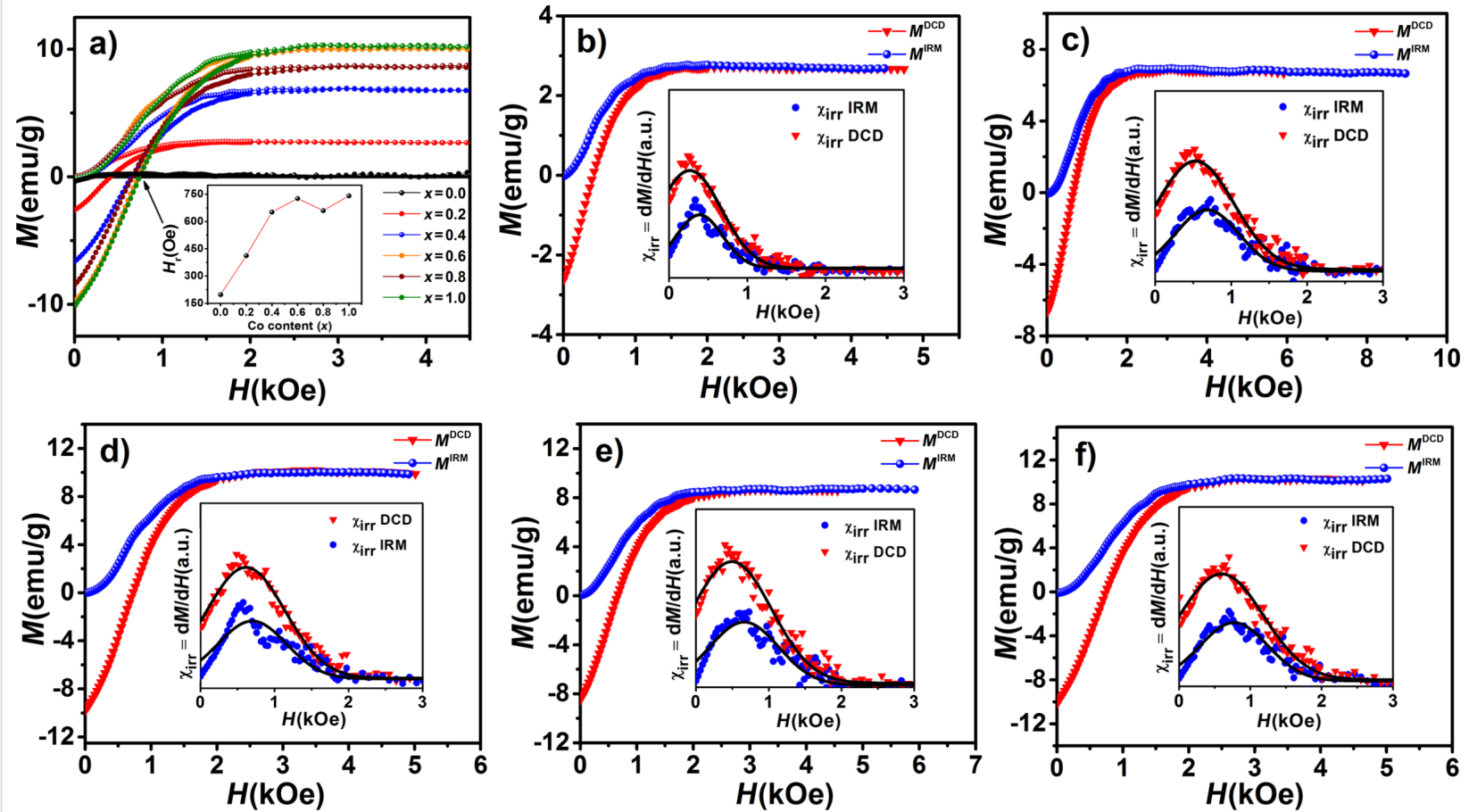

Figure 11: IRM and DCD magnetization curves of (a) all $\mathrm{Co}_{x} \mathrm{Fe}_{3-x} \mathrm{O}_{4}$ samples and separately for (b) $x=0.2$, (c) $x=0.4$, (d) $x=0.6$, (e) $x=0.8$ and (f) $x=1$. The inset in (a) shows the reverse field as a function of $x$. The other insets show the irreversible susceptibility $X_{\text {irr }}$ obtained from $M^{\mathrm{IRM}}$ and $M^{\mathrm{DCD}}$ curves. 
tion 8), the Henkel plot of non-interacting nanoparticles should yield a linear function with a slope of -2 . Hence, a deviation from linear behavior indicates the presence of interactions between nanoparticles. Kelly et al. showed that in interacting systems, the Henkel plot has a deviation from linearity by an amount of $\delta m=m^{\mathrm{DCD}}(H)-\left(1-2 m^{\left.\mathrm{IRM}_{(}\right)}\right)$[44-46]. In particular, a negative peak (a negative deviation of the Henkel plot) in the $\delta m$ curve indicates the dominance of dipole-dipole interactions, while a positive peak (a positive deviation of the Henkel plot) can be attributed to the dominance of exchange interactions. This is because the dipole-dipole interactions tend to hinder the magnetization (i.e., they have the effect of stabilizing the demagnetized state), while the exchange interactions promote a magnetization. Also, the intensity of the dip of the $\delta m$ curve depends on the strength of the interactions $[9,47,48]$. The strength of the interactions can be estimated by calculating the mean interaction field $\left(H_{\text {int }}\right)$ defined as $[46,47]$ :

$$
H_{\mathrm{int}}=\frac{H^{\mathrm{DCD}}-H^{\mathrm{IRM}}}{2},
$$

where $H^{\mathrm{DCD}}$ and $H^{\mathrm{IRM}}$ correspond to the peak position of the $\chi_{\text {irr }}$ (DCD) and the $\chi_{\text {irr }}$ (IRM) curve, respectively (see Figure 11). In our case, the obtained negative values for $H_{\text {int }}$ (Table 3) confirmed the presence of dipole-dipole interactions in all samples. The corresponding $\delta m$ curves and Henkel plots are shown in Figure. 12. The interaction field increases with increasing cobalt content, which can be related to the particle size and the larger magnetic moment of bigger nanoparticles $[13,47]$. The particle aggregation visible in FE-SEM images shows that the particles are interacting.

The $\delta m$ plot in Figure 12 indicates that the magnetic interactions between particles are weakest in in the $x=0.6$ sample. This is in good agreement with the $H_{\text {int }}$ value and FE-SEM observations. The origin of the low intensity of the $\delta m$ plot of the $x=0.8$ sample can be attributed to the smaller particle size, which is clearly visible in the FE-SEM images (Figure 3).

\section{Magnetic hyperthermia}

In order to study the heat generation of the nanoparticles for a potential use in magnetic hyperthermia therapy, the samples were dispersed into deionized water at the same concentration $(111 \mathrm{mg} / \mathrm{mL})$ and exposed to an ac magnetic field. The increasing temperature as a function of the time was measured. Figure 13 shows a remarkable result, the temperature rise in the $x=0$ sample with the smallest anisotropy and particle size was much larger than that of the other samples.

Recently, a similar behavior was reported for $\mathrm{Ni}_{x} \mathrm{Co}_{1-x} \mathrm{Fe}_{2} \mathrm{O}_{4}$ by Caetano and co-workers [15]. They showed that the heat

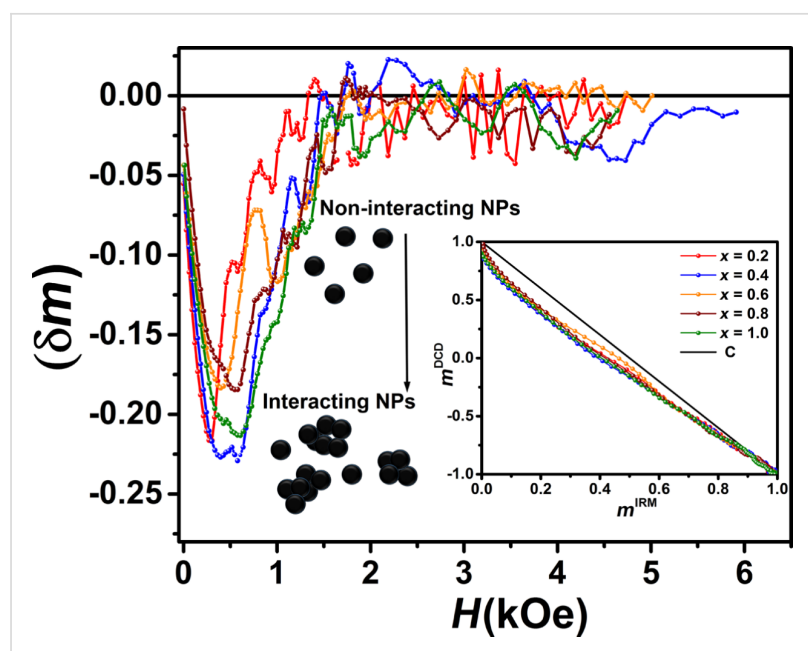

Figure 12: $\delta m$ as a function of the magnetic field strength measured at room temperature. The inset shows the Henkel plots.

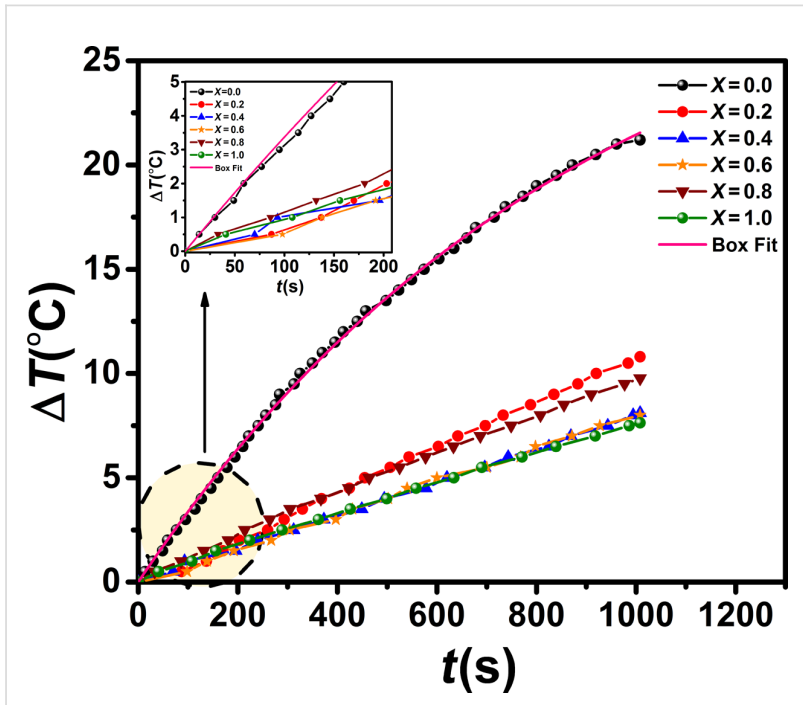

Figure 13: Temperature rise in $\mathrm{Co}_{x} \mathrm{Fe}_{3-x} \mathrm{O}_{4}$ suspensions in an ac magnetic field $(27 \mathrm{Oe}, 92 \mathrm{kHz})$ as a function of the time. The inset shows the temperature rise in the first $200 \mathrm{~s}$. The pink straight line for $x=0$ is a fit resulting from the Box-Lucas model.

generation increases with Ni content because of an increase of the minor hysteresis loop area. Our results can be related to the magnetic anisotropy of the NPs. When the coercivity of the NPs is larger than the field amplitude $(H)$, the magnetization does not reach complete saturation and exhibits minor loops.

In order to characterize the SAR value of the samples, the curves of the temperature as a function of the time were fitted by the Box-Lucas model, $T(t)=A \cdot\left(1-e^{-B t}\right)$, where $A$ is the saturation temperature and $B$ is a fit parameter. Here, the product $A \cdot B$ is the initial rate of the temperature rise. It is equivalent to the ratio $\mathrm{d} T / \mathrm{d} t$ in the following equation $[49,50]$ : 


$$
\mathrm{SAR}=c_{\mathrm{p}} \frac{m_{\mathrm{s}}}{m_{\mathrm{n}}} \frac{\mathrm{d} T}{\mathrm{~d} t}
$$

where $c_{\mathrm{p}}$ is the specific heat capacity of the solution (here $c_{\mathrm{p}}=4.18 \mathrm{~J} /(\mathrm{g} \cdot \mathrm{K})$ for water), $m_{\mathrm{s}}$ is the mass of the solution, $m_{\mathrm{s}}$ is the mass of the nanoparticles and $\mathrm{d} T / \mathrm{d} t$ is the initial slope of the heating curves. Figure 13 shows the fit curve using the Box-Lucas model (solid line) for the $x=0$ sample. The SAR value, or specific loss power (SLP), was then obtained by using Equation 10.

The SAR value is commonly used to characterize the behavior in magnetic hyperthermia. However, it is not an intrinsic property of a given system. It depends on the field amplitude and frequency. Therefore, the intrinsic loss power (ILP) parameter also is useful to compare the heating behavior measured under different values of $f$ and $H$ [51,52]:

$$
\mathrm{ILP}=\frac{\mathrm{SAR}}{H^{2} f} .
$$

The values of SAR and ILP decrease with increasing cobalt content. This is because in the samples containing cobalt $\left(H_{\mathrm{c}}>H\right)$ the system exhibits minor loops with a slight hysteresis losses.

\section{Conclusion}

In the present paper, we studied the effect of Co doping on the structural, magnetic and hyperthermia properties of $\mathrm{Co}_{x} \mathrm{Fe}_{3-x} \mathrm{O}_{4}$ nanoparticles. The substitution of $\mathrm{Fe}$ by Co leads to an increase of crystallite size, saturation magnetization, coercivity and especially of the magnetic anisotropy of the nanoparticles. Interparticle interactions were disclosed by Henkel plots and $\delta m$ curves. The negative deviation of the Henkel plots from linearity as well as the negative $\delta m$ curves indicate a predominance of dipole-dipole interactions in all samples. It was observed that Co doping strongly reduces the specific absorption rate values (to about a fourth) in the samples, despite increasing the magnetic anisotropy, saturation magnetization and particle size. Our results showed that the heat-generation efficiency is highly impacted by the magnetic anisotropy of the nanoparticles.

\section{Experimental Synthesis}

$\mathrm{Co}_{x} \mathrm{Fe}_{3-x} \mathrm{O}_{4}$ nanoparticles were synthesized using a facile co-precipitation method at $80{ }^{\circ} \mathrm{C}$ in air. The chemical reaction can be written as follows:

$$
\begin{aligned}
& 2 \mathrm{FeCl}_{3} \cdot 6 \mathrm{H}_{2} \mathrm{O}+(1-x) \mathrm{FeCl}_{2} \cdot 4 \mathrm{H}_{2} \mathrm{O} \\
& +x \mathrm{CoCl}_{2} \cdot 4 \mathrm{H}_{2} \mathrm{O}+8 \mathrm{NaOH} \\
& \rightarrow \mathrm{Co}_{x} \mathrm{Fe}_{3-x} \mathrm{O}_{4}+8 \mathrm{NaCl}+14 \mathrm{H}_{2} \mathrm{O}
\end{aligned}
$$

In the first step, stoichiometric amounts of the starting material (see Table 5), including $\mathrm{FeCl}_{3} \cdot 6 \mathrm{H}_{2} \mathrm{O}$ (Merck, 99\%), $\mathrm{FeCl}_{2} \cdot 4 \mathrm{H}_{2} \mathrm{O}$ (Carlo Erba, 99\%) and $\mathrm{CoCl}_{2} \cdot 4 \mathrm{H}_{2} \mathrm{O}$ (Merck, 99\%) were mixed and dissolved in $50 \mathrm{~mL}$ of deionized water. Also, $\mathrm{NaOH}$ was separately weighed and dissolved in $50 \mathrm{~mL}$ deionized water to a concentration of $8.0 \mathrm{M}$. In the second step, the temperature of the metal-salt solution was raised $80{ }^{\circ} \mathrm{C}$ under stirring. Then, the aqueous solution of $\mathrm{NaOH}$ was added quickly to the solution at $80^{\circ} \mathrm{C}$. The obtained black slurry was constantly stirred at $80^{\circ} \mathrm{C}$ for $30 \mathrm{~min}$. The prepared nanoparticles were washed with deionized water for several times and, finally, dried at room temperature for $24 \mathrm{~h}$.

\section{Characterization techniques}

\begin{tabular}{|c|c|c|c|c|c|c|}
\hline parameter & $x=0$ & $x=0.2$ & $x=0.4$ & $x=0.6$ & $x=0.8$ & $x=1$ \\
\hline $\operatorname{SAR}(\mathrm{W} / \mathrm{g})$ & 1.33 & 0.44 & 0.34 & 0.32 & 0.49 & 0.37 \\
\hline ILP $\left(\mathrm{nH} \cdot \mathrm{m}^{2} / \mathrm{kg}\right)$ & 3.13 & 1.04 & 0.80 & 0.75 & 1.15 & 0.87 \\
\hline
\end{tabular}

Phase purity and crystalline structure of the samples were characterized by using a Philips X'Pert Pro MPDX-ray diffractometer (XRD) with $\mathrm{Cu} \mathrm{K} \alpha(\lambda=0.154 \mathrm{~nm})$ radiation. The diffraction patterns were analyzed using the FullProf-Suite

Table 5: Amounts of the starting materials to prepare $1.5 \mathrm{~g}$ of $\mathrm{Co}_{x} \mathrm{Fe}_{3-x} \mathrm{O}_{4}$ nanoparticles.
\begin{tabular}{lllllr} 
material & $x=0$ & $x=0.2$ & $x=0.4$ & $x=0.6$ & $x=0.8$ \\
\hline$m\left(\mathrm{FeCl}_{3} \cdot 6 \mathrm{H}_{2} \mathrm{O}\right)(\mathrm{g})$ & 3.502 & 3.493 & 3.484 & 3.475 & 3.465 \\
$m\left(\mathrm{FeCl}_{2} \cdot 4 \mathrm{H}_{2} \mathrm{O}\right)(\mathrm{g})$ & 1.288 & 1.027 & 0.768 & 0.511 & 0.255 \\
$m\left(\mathrm{CoCl}_{2} \cdot 4 \mathrm{H}_{2} \mathrm{O}\right)(\mathrm{g})$ & 0.000 & 0.307 & 0.613 & 0.918 & 1.220 \\
\end{tabular}


(Version 6.0) software. Thermogravimetric analysis (TGA) was carried out in the temperature range from 30 to $650{ }^{\circ} \mathrm{C}$ with a heating rate of $10{ }^{\circ} \mathrm{C} / \mathrm{min}$ under $\mathrm{N}_{2}$ flow using a TGA/SDTA 851 Mettler Toledo thermogravimetric analyzer. Fourier transform infrared (FTIR) spectra of the samples were obtained in the range of $400-4000 \mathrm{~cm}^{-1}$ by pressing the powders in $\mathrm{KBr}$ pellets. The morphology and elemental chemical composition of the samples were investigated using a Tescan Mira 3 fieldemission scanning electron microscope (FE-SEM) equipped with an energy-dispersive X-ray spectrometer. The magnetic properties were studied at room temperature by a custom-built vibrating sample magnetometer (VSM) with a maximum applied field of $18 \mathrm{kOe}$. The field-dependence of remanent magnetization was measured by following the isothermal remanent magnetization $\left(M^{\mathrm{IRM}}\right)$ and direct current demagnetization $\left(M^{\mathrm{DCD}}\right)$ protocols. For the $M^{\mathrm{IRM}}$ measurement, an external field was applied to a demagnetized sample, then it was switched off and the remanent magnetization was measured. This process was repeated, increasing the field up to $18 \mathrm{kOe}$. In the $M^{\mathrm{DCD}}$ measurement, the samples were magnetized at $-18 \mathrm{kOe}$. After that, a small field in the opposite direction of magnetization was applied, then the field was switched off and the remanence $M^{\mathrm{DCD}}$ was measured. This process was repeated increasing the field strength up to $+18 \mathrm{kOe}$. Magnetic hyperthermia properties were studied by using a custom-built setup at a frequency of $92 \mathrm{kHz}$ and a field amplitude of $27 \mathrm{Oe}$.

\section{Acknowledgements}

The University of Tabriz is acknowledged for financial support. The authors thank to Dr. I. Orue from Sgiker (UPV/EHU) and Prof. P. Kameli from Isfahan University of Technology for technical and human support.

\section{ORCID ${ }^{\circledR}$ iDs}

Bagher Aslibeiki - https://orcid.org/0000-0003-3366-0761

Volodymyr A. Chernenko - https://orcid.org/0000-0002-0933-9372

\section{References}

1. Muscas, G.; Concas, G.; Laureti, S.; Testa, A. M.; Mathieu, R.; De Toro, J. A.; Cannas, C.; Musinu, A.; Novak, M. A.; Sangregorio, C.; Lee, S. S.; Peddis, D. Phys. Chem. Chem. Phys. 2018, 20, 28634-28643. doi:10.1039/c8cp03934h

2. Pan, S.; Liu, Z.; Lu, W. Nanotechnology 2019, 30, 065605. doi:10.1088/1361-6528/aaf17c

3. Mameli, V.; Musinu, A.; Ardu, A.; Ennas, G.; Peddis, D.; Niznansky, D.; Sangregorio, C.; Innocenti, C.; Thanh, N. T. K.; Cannas, C. Nanoscale 2016, 8, 10124-10137. doi:10.1039/c6nr01303a

4. Usov, N. A.; Nesmeyanov, M. S.; Gubanova, E. M.; Epshtein, N. B. Beilstein J. Nanotechnol. 2019, 10, 305-314. doi:10.3762/bjnano.10.29

5. Kefeni, K. K.; Msagati, T. A. M.; Mamba, B. B. Mater. Sci. Eng., B 2017, 215, 37-55. doi:10.1016/j.mseb.2016.11.002

6. Deshmukh, R.; Mehra, A.; Thaokar, R. Beilstein J. Nanotechnol. 2017, 8, 494-505. doi:10.3762/bjnano.8.53
7. Gutiérrez, L.; de la Cueva, L.; Moros, M.; Mazarío, E.; de Bernardo, S.; de la Fuente, J. M.; Morales, M. P.; Salas, G. Nanotechnology 2019, 30, 112001. doi:10.1088/1361-6528/aafbff

8. Serantes, D.; Simeonidis, K.; Angelakeris, M.; Chubykalo-Fesenko, O.; Marciello, M.; Del Puerto Morales, M.; Baldomir, D.; Martinez-Boubeta, C. J. Phys. Chem. C 2014, 118, 5927-5934. doi:10.1021/jp410717m

9. De Toro, J. A.; Vasilakaki, M.; Lee, S. S.; Andersson, M. S.; Normile, P. S.; Yaacoub, N.; Murray, P.; Sánchez, E. H.; Muñiz, P.; Peddis, D.; Mathieu, R.; Liu, K.; Geshev, J.; Trohidou, K. N.; Nogués, J. Chem. Mater. 2017, 29, 8258-8268. doi:10.1021/acs.chemmater.7b02522

10. Routray, K. L.; Saha, S.; Behera, D. Mater. Sci. Eng., B 2017, 226 , 199-205. doi:10.1016/j.mseb.2017.09.021

11. Mohapatra, J.; Xing, M.; Liu, J. P. AIP Adv. 2018, 8, 056725. doi:10.1063/1.5006515

12. Sathya, A.; Guardia, P.; Brescia, R.; Silvestri, N.; Pugliese, G.; Nitti, S.; Manna, L.; Pellegrino, T. Chem. Mater. 2016, 28, 1769-1780. doi:10.1021/acs.chemmater.5b04780

13. Aslibeiki, B. Ceram. Int. 2016, 42, 6413-6421. doi:10.1016/j.ceramint.2016.01.044

14. Lambruschini, C.; Villa, S.; Banfi, L.; Canepa, F.; Morana, F.; Relini, A.; Riani, P.; Riva, R.; Silvetti, F. Beilstein J. Nanotechnol. 2018, 9 , 986-999. doi:10.3762/bjnano.9.92

15. Caetano, P. M. A.; Albuquerque, A. S.; Fernandez-Outon, L. E.; Macedo, W. A. A.; Ardisson, J. D. J. Alloys Compd. 2018, 758, 247-255. doi:10.1016/j.jallcom.2018.05.124

16. Najafinezhad, A.; Abdellahi, M.; Saber-Samandari, S.; Ghayour, H.; Khandan, A. J. Alloys Compd. 2018, 734, 290-300. doi:10.1016/j.jallcom.2017.10.138

17. Verde, E. L.; Landi, G. T.; Carrião, M. S.; Drummond, A. L.; Gomes, J. A.; Vieira, E. D.; Sousa, M. H.; Bakuzis, A. F. AIP Adv. 2012, 2, 032120. doi:10.1063/1.4739533

18. Nemati, Z.; Alonso, J.; Martinez, L. M.; Khurshid, H.; Garaio, E.; Garcia, J. A.; Phan, M. H.; Srikanth, H. J. Phys. Chem. C 2016, 120 , 8370-8379. doi:10.1021/acs.jpcc.6b01426

19. Le, A.-T.; Giang, C. D.; Tam, L. T.; Tuan, T. Q.; Phan, V. N.; Alonso, J.; Devkota, J.; Garaio, E.; García, J. Á.; Martín-Rodríguez, R.; Fdez-Gubieda, M. L.; Srikanth, H.; Phan, M.-H. Nanotechnology 2016, 27, 155707. doi:10.1088/0957-4484/27/15/155707

20. Orozco-Henao, J. M.; Coral, D. F.; Muraca, D.; Moscoso-Londoño, O.; Mendoza Zélis, P.; Fernandez van Raap, M. B.; Sharma, S. K.; Pirota, K. R.; Knobel, M. J. Phys. Chem. C 2016, 120, 12796-12809. doi:10.1021/acs.jpcc.6b00900

21. Nemati, Z.; Salili, S. M.; Alonso, J.; Ataie, A.; Das, R.; Phan, M. H.; Srikanth, H. J. Alloys Compd. 2017, 714, 709-714. doi:10.1016/j.jallcom.2017.04.211

22. Barrera, G.; Coisson, M.; Celegato, F.; Raghuvanshi, S.; Mazaleyrat, F.; Kane, S. N.; Tiberto, P. J. Magn. Magn. Mater. 2018, 456, 372-380. doi:10.1016/j.jmmm.2018.02.072

23. Fantechi, E.; Innocenti, C.; Albino, M.; Lottini, E.; Sangregorio, C. J. Magn. Magn. Mater. 2015, 380, 365-371. doi:10.1016/j.jmmm.2014.10.082

24. Anjum, S.; Tufail, R.; Rashid, K.; Zia, R.; Riaz, S. J. Magn. Magn. Mater. 2017, 432, 198-207. doi:10.1016/j.jmmm.2017.02.006

25. Luo, Y.-R. Comprehensive Handbook of Chemical Bond Energies; CRC Press: Boca Raton, FL, U.S.A., 2007. doi:10.1201/9781420007282 
26. Kalska-Szostko, B.; Wykowska, U.; Satula, D.; Nordblad, P. Beilstein J. Nanotechnol. 2015, 6, 1385-1396. doi:10.3762/bjnano.6.143

27. Yang, M.-H.; Yuan, S.-S.; Chung, T.-W.; Jong, S.-B.; Lu, C.-Y.; Tsai, W.-C.; Chen, W.-C.; Lin, P.-C.; Chiang, P.-W.; Tyan, Y.-C. BioMed Res. Int. 2014, 1-13. doi:10.1155/2014/209469

28. Sharma, R.; Thakur, P.; Sharma, P.; Sharma, V. J. Alloys Compd. 2017, 704, 7-17. doi:10.1016/j.jallcom.2017.02.021

29. Aslibeiki, B. Curr. Appl. Phys. 2014, 14, 1659-1664. doi:10.1016/j.cap.2014.09.025

30. Kombaiah, K.; Vijaya, J. J.; Kennedy, L. J.; Bououdina, M.; Al Najar, B. J. Alloys Compd. 2018, 735, 1536-1545. doi:10.1016/j.jallcom.2017.11.279

31. Wang, Z.; Wang, W.; Zhang, L.; Jiang, D. Catal. Sci. Technol. 2016, 6, 3845-3853. doi:10.1039/c5cy01709b

32. Aslibeiki, B.; Kameli, P.; Ehsani, M. H.; Salamati, H.; Muscas, G.; Agostinelli, E.; Foglietti, V.; Casciardi, S.; Peddis, D.

J. Magn. Magn. Mater. 2016, 399, 236-244. doi:10.1016/j.jmmm.2015.09.081

33. Kumar, K.; Loganathan, A. Mater. Sci. Eng., B 2017, 224, 48-55. doi:10.1016/j.mseb.2017.07.007

34. Aslibeiki, B.; Varvaro, G.; Peddis, D.; Kameli, P. J. Magn. Magn. Mater. 2017, 422, 7-12. doi:10.1016/j.jmmm.2016.08.057

35. Virumbrales-del Olmo, M.; Delgado-Cabello, A.; Andrada-Chacón, A.; Sánchez-Benítez, J.; Urones-Garrote, E.; Blanco-Gutiérrez, V.; Torralvo, M. J.; Sáez-Puche, R. Phys. Chem. Chem. Phys. 2017, 19, 8363-8372. doi:10.1039/c6cp08743d

36. Aslibeiki, B.; Ehsani, M. H.; Nasirzadeh, F.; Mohammadi, M. A. Mater. Res. Express 2017, 4, 075051. doi:10.1088/2053-1591/aa7eb1

37. Li, D.; Yun, H.; Diroll, B. T.; Doan-Nguyen, V. V. T.; Kikkawa, J. M.; Murray, C. B. Chem. Mater. 2016, 28, 480-489. doi:10.1021/acs.chemmater.5b03280

38. Sharma, R.; Thakur, P.; Kumar, M.; Thakur, N.; Negi, N. S.; Sharma, P.; Sharma, V. J. Alloys Compd. 2016, 684, 569-581. doi:10.1016/j.jallcom.2016.05.200

39. Betancourt-Galindo, R.; Ayala-Valenzuela, O.; García-Cerda, L. A.; Rodríguez Fernández, O.; Matutes-Aquino, J.; Ramos, G.; Yee-Madeira, H. J. Magn. Magn. Mater. 2005, 294, e33-e36. doi:10.1016/j.jmmm.2005.03.049

40. Li, X.; Kutal, C. J. Alloys Compd. 2003, 349, 264-268. doi:10.1016/s0925-8388(02)00863-0

41. Deepak, F. L.; Bañobre-López, M.; Carbó-Argibay, E.; Cerqueira, M. F.; Piñeiro-Redondo, Y.; Rivas, J.; Thompson, C. M.; Kamali, S.; Rodríguez-Abreu, C.; Kovnir, K.; Kolen'ko, Y. V. J. Phys. Chem. C 2015, 119, 11947-11957. doi:10.1021/acs.jpcc.5b01575

42. Ghunaim, R.; Scholz, M.; Damm, C.; Rellinghaus, B.; Klingeler, R.; Büchner, B.; Mertig, M.; Hampel, S. Beilstein J. Nanotechnol. 2018, 9, 1024-1034. doi:10.3762/bjnano.9.95

43. Cannas, C.; Musinu, A.; Ardu, A.; Orru, F.; Peddis, D.; Casu, M.; Sanna, R.; Angius, F.; Diaz, G.; Piccaluga, G. Chem. Mater. 2010, 22 , 3353-3361. doi:10.1021/cm903837g

44. Kelly, P. E.; O'Grady, K.; Mayo, P. I.; Chantrell, R. W. IEEE Trans. Magn. 1989, 25, 3881-3883. doi:10.1109/20.42466

45. Fabris, F.; Xing, Y. T.; Franceschini, D. F.; Sanchez, D. R.; Alzamora, M.; Nunes, W. C. J. Appl. Phys. 2017, 122, 063901. doi:10.1063/1.4985789

46. Coral, D. F.; Mendoza Zélis, P.; Marciello, M.; Morales, M. d. P.; Craievich, A.; Sánchez, F. H.; Fernández van Raap, M. B. Langmuir 2016, 32, 1201-1213. doi:10.1021/acs.langmuir.5b03559
47. Lavorato, G. C.; Peddis, D.; Lima, E., Jr.; Troiani, H. E.; Agostinelli, E.; Fiorani, D.; Zysler, R. D.; Winkler, E. L. J. Phys. Chem. C 2015, 119, 15755-15762. doi:10.1021/acs.jpcc.5b04448

48. Ojha, S.; Nunes, W. C.; Aimon, N. M.; Ross, C. A. ACS Nano 2016, 10, 7657-7664. doi:10.1021/acsnano.6b02985

49. Jadhav, S. V.; Kim, B. M.; Lee, H. Y.; Im, I. C.; Rokade, A. A.; Park, S. S.; Patil, M. P.; Kim, G. D.; Yu, Y. S.; Lee, S. H. J. Alloys Compd. 2018, 745, 282-291. doi:10.1016/j.jallcom.2018.02.174

50. Ralandinliu Kahmei, R. D.; Borah, J. P. Nanotechnology 2019, 30, 035706. doi:10.1088/1361-6528/aaecc5

51. Cruz, M. M.; Ferreira, L. P.; Ramos, J.; Mendo, S. G.; Alves, A. F.; Godinho, M.; Carvalho, M. D. J. Alloys Compd. 2017, 703, 370-380. doi:10.1016/j.jallcom.2017.01.297

52. Zargar, T.; Kermanpur, A. Ceram. Int. 2017, 43, 5794-5804. doi:10.1016/j.ceramint.2017.01.127

\section{License and Terms}

This is an Open Access article under the terms of the Creative Commons Attribution License (http://creativecommons.org/licenses/by/4.0). Please note that the reuse, redistribution and reproduction in particular requires that the authors and source are credited.

The license is subject to the Beilstein Journal of

Nanotechnology terms and conditions:

(https://www.beilstein-journals.org/bjnano)

The definitive version of this article is the electronic one which can be found at: doi:10.3762/bjnano.10.133 